Marco Antonio Merchand Rojas*

Universidad de Guadalajara, Guadalajara, México.

Recibido: 5 de marzo de 2014

Concepto de evaluación: 16 de junio de 2014

Aprobado: 18 de junio de 2014

Artículo de reflexión (C) 2014 Universidad Católica de Colombia. Facultad de Ciencias Económicas y Administrativas. Todos los derechos reservados

\title{
¿Es México un Estado reproductor de las desigualdades regionales?
}

\section{RESUMEN}

En este artículo se analiza cómo el Estado mexicano en lugar de haber aminorado los grados de desigualdad, estos se han promovido e, incluso, de cierta manera, han sido fomentados para generar un desarrollo regional más desequilibrado y desarticulado en función únicamente de los intereses sectoriales predominantes, sean agrícolas, industriales y de servicios; pues solo se buscan espacios económicos que permitan reproducir capitales espurios (enclaves económicos), sin una contribución a las comunidades locales; incluso, muchas veces, se han generado externalidades negativas que socavan el tejido social de las poblaciones locales. A lo largo de los siguientes párrafos, se explica cómo el Estado mexicano en estos últimos treinta años se ha mostrado solo como instancia regulativa y promotora de un crecimiento económico excluyente a favor del capital y en contra del trabajo. Además, es un Estado incapaz de sostener o asegurar las condiciones mínimas (económicas y sociales) para que los espacios nacionales y locales reproduzcan su tejido productivo y se permita que estos muestren un trayecto histórico consolidado; por el contrario, han surgido espacios con sinergias negativas irreversibles.

Palabras clave: Estado, desigualdad, regiones, economía y política.

JEL: P00, P16

\section{Is Mexico a State that Reproduces Regional Inequalities?}

* Doctor en Ciencias Sociales. Profesor del Departamento de Sociedad y Economía del Centro Universitario del Sur, Universidad de Guadalajara, Guadalajara, México. Dirección de correspondencia: Real de Montes Urales 333. Lomas de la Higuera, Villa de Álvarez, Colima 28979. Correo electrónico: marco.merchand@cusur.udg.mx

\section{ABSTRACT}

This article analyzes how the Mexican State has promoted inequality levels instead of decreasing them. These levels have also been promoted to generate a more unbalanced and disassembled regional development just in favor of the prevailing sectorial interests whereas in agriculture, the industries or the service sector, because these just look for economical spaces that allow to reproduce spurious resources (economic enclaves) without a contribution to local communities. Negative externalities indeed affect many times and 
undermine the social network of local populations. Throughout the following paragraphs, it will be explained how the Mexican State, in these last thirty years, has shown itself just as regulatory and sponsoring instance of an increasingly exclusive economic growth, in favor of capital and against work. Besides that, this State is unable of holding or guaranteeing minimum conditions (economic and social) for national and local spaces to recreate their reproductive network so they could show a historical and consolidated route; on the contrary, spaces with irreversible negative synergies have emerged.

Keywords: State, inequality, regions, economics and politics.

\section{É o México um Estado reproductor de desigualdades regionais?}

\section{RESUMO}

Neste artigo, analisa-se como o Estado mexicano, em lugar de ter diminuído os graus de desigualdade, estes têm sido promovidos e, inclusive, de certo modo, fomentados para gerar um desenvolvimento regional mais desequilibrado e desarticulado em função unicamente dos interesses setoriais predominantes, sejam agrícolas, industriais e de serviços; pois só se buscam espaços econômicos que permitam reproduzir capitais espúrios (enclaves econômicos), sem uma contribuição para as comunidades locais; muitas vezes, externalidades negativas que debilitam o tecido social das populações locais. Ao longo dos seguintes parágrafos, explica-se como o Estado mexicano nestes últimos trinta anos vem se mostrando só como instância reguladora e promotora de um crescimento econômico excludente a favor do capital e contra o trabalho. Além disso, é um Estado incapaz de sustentar ou garantir as condições mínimas (econômicas e sociais) para que os espaços nacionais e locais reproduzam seu tecido produtivo e permita-se que estes mostrem um trajeto histórico consolidado; pelo contrário, têm surgido espaços com sinergias negativas irreversíveis.

Palavras-chave: Estado, desigualdade, regiões, economia e política. 


\section{INTRODUCCIÓN}

Respecto al planteamiento metodológico sobre el estado del arte objeto de estudio, se plantea una visión metodológica que sustenta la premisa de que dadas las condiciones como se engendra el capitalismo y sus mecanismos de expansión (por ejemplo, derechos exclusivos de propiedad privada sobre los comunales y/o comunitarios, mercantilización del espacio basado en procesos coloniales e imperiales) dicho capitalismo extractivo y depredador reproduzca exponencialmente cada vez más las brechas económicas y sociales entre regiones mundiales, nacionales y locales.

En otras palabras, la economía capitalista cuenta con una naturaleza inherente de reproducir desarrollo desigual, e incluso esta es una estrategia que le es propia al capital para poder expandirse en los ámbitos mundiales, nacionales, regionales y locales en los niveles inter e intra (el imperialismo formal e informal —coloniaje- aprovecha estas desigualdades para poder expandirse mundialmente). Es decir, el proceso de desarrollo económico capitalista es un proceso desigual, que no afecta de manera uniforme a todas las regiones y países; son los patrones de distribución territorial (ordenamiento territorial excluyente) los que determinan en última instancia las perspectivas de un desarrollo regional desigual. En decir, el sistema de producción capitalista no es un sistema diseñado para ampliar el bienestar de los habitantes de un país, sus metas son las máximas ganancias y tasas de acumulación. Estas metas son incompatibles con un nivel de concentración de riqueza económica y aumento generalizado en el nivel de bienestar social.

El modelo neoliberal ${ }^{1}$ adoptado ha tenido y sigue teniendo un efecto de "suma cero", ya que

1 Carlos Tello y Jorge Ibarra (2013) nos muestran cómo el neoliberalismo crea un mundo de individuos e idealiza el espacio que ocupan como un mercado libre y consumista; nos muestran asimismo cómo fueron derruidos Gobiernos de sentido social; cómo los funcionarios públicos adquirieron una mentalidad de empresarios; cómo el mejor Gobierno consiste en la autorregulación del mercado, vale decir, el mejor Gobierno es el no-Gobierno. Examinan así minuciosamente la desregulación de la economía; la liberalización del comercio y la industria, la privatización de las empresas públicas, cómo se reducen los impuestos y el gasto público, mientras unas regiones resultan ganadoras con la apertura comercial, otras tienen pérdidas que contrarrestan el efecto positivo de aquellas regiones ganadores. Es decir, lo que unos ganan es lo que otros pierden; en este sentido, el saldo neto sería la diferencia entre el valor más alto de crecimiento del PIB en un Estado (entidad federativa) y el valor más bajo registrado en este mismo indicador, en otros Estados o entidades federativas.

El enfoque conceptual básico que sustenta los siguientes argumentos es el concepto de neoliberalismo realmente existente que explican Brenner y Theodore (2002) y que consiste en proponer que este neoliberalismo no es puro, ya que implica la consideración de las interacciones dependientes de las contextualizaciones específicas de escenarios regulatorios heredados y proyectos emergentes de reformas orientadas al mercado. Es decir, la imposición global del modelo neoliberal ha sido desigual en términos sociales y geográficos, sus formas institucionales y consecuencias sociopolíticas han variado significativamente a través de diversas escalas espaciales. En el caso de México se muestra cómo las desigualdades inter e intrarregionales y estatales son producto de sus condiciones históricas que definen su statu quo en el escenario nacional y regional.

¿Cómo ha operado ese neoliberalismo realmente existente que proponen Brenner y Theodore en México? Este planteamiento general se concretiza en analizar cómo el equilibrio estable de los fundamentos macroeconómicos clave, que tan preocupados tienen al Fondo Monetario Internacional (FMI) y al Banco Mundial (BM) y por supuesto a la tecnocracia neoliberal mexicana (estabilidad de los precios, tipo de cambio como ancla antiinflacionaria, altas tasas de interés y rígidas políticas de austeridad fiscal) se ha logrado para ofrecer garantías al capital; sin embargo, el costo de oportunidad ha sido muy alto para lograr la ansiada estabilidad, pues se manifiesta un detrimento creciente en las condiciones de vida de la

cómo eliminan las medidas de protección social, y más. Y lo peor, cómo lograron vencer a izquierdas de distintos tipos que cedieron a los embates ideológicos neoliberales. 
gran mayoría de la población y se muestran signos inequívocos de estrangulamientos estructurales (sociales, sectoriales y regionales).

Estos escenarios macroeconómicos favorables al capital a través de políticas de ajuste han sido adversos al bienestar social mayoritario, y este deterioro se ha manifestado en disparidades regionales entre entidades que crecen por arriba de la media (PIB per cápita) y otros Estados en claro descenso en su participación, como son los Estados de Chiapas, Guerrero y Oaxaca. Así pues, este trabajo está estructurado en dos apartados:

1. Los efectos de la política económica en el crecimiento económico.

2. El Estado y las desigualdades regionales.

\section{LOS EFECTOS DE LA POLÍTICA ECONÓMICA EN EL CRECIMIENTO ECONÓMICO}

El concepto articulador de este primer apartado se basa en el postulado de que la llamada "globalización económica" que conlleva la ilusión de ofrecer un "desarrollo económico" no es equivalente a lo que denominamos "desarrollo total" de una sociedad, ya que este se refiere solo a una dimensión parcial del proceso: la estrictamente económica. El cuestionamiento que nos hacemos es a qué se debe que la globalización económica sea una quimera, donde se visualiza más la otra cara de su moneda, la exclusión social en sus ámbitos (local, regional, nacional y mundial).

De acuerdo con el informe del BM (2005), realizado por Ferranti, Perry, Ferreira y Walton, América Latina es altamente desigual en cuanto a ingresos y también en el acceso a servicios como educación, salud, agua y electricidad; y persisten además enormes disparidades en términos de participación, bienes y oportunidades. Esta situación frena el ritmo de la reducción de la pobreza y mina el proceso de desarrollo en sí. Los investigadores mencionados usaron también el índice de Gini para medir la desigualdad en la distribución del ingreso y el consumo, y descubrieron que desde la década de los setenta hasta la de los noventa la desigualdad en América Latina y el Caribe fue superior en 10 puntos respecto de Asia; en 17,5 puntos respecto de los 30 países de la OCDE y 20,4 puntos respecto de Europa oriental.

Aquí cabría preguntarse en el mismo tenor que lo hace el BM si está empeorando la desigualdad. Durante la década pasada, surgieron diversos patrones con respecto a las diferencias de ingresos, según los cuales más países están experimentando una tendencia al empeoramiento más que al mejoramiento.

En el caso de México, entre 1994 y 2000 la pobreza pasó del $51 \%$ al $70 \%$ de la población. EI $20 \%$ más pobre bajó su participación en el ingreso de $3,6 \%$ a $2,9 \%$, mientras que el $10 \%$ más rico la aumentó del $44 \%$ al $50 \%$ (Boltvinik, 2001). Sin embargo, para el propio BM, la pobreza en México bajó de una tasa de $24,2 \%$ a $17,6 \%$ en los últimos cuatro años, nivel bastante considerable, de acuerdo con la directora para Colombia y México del BM, Isabel Guerrero Pulgar, quien señaló que la pobreza urbana ha sido mucho más difícil de reducir, mientras que la rural presentó una baja de $42 \%$ a $27,9 \%$ de la población en pobreza extrema.

La globalización económica neoliberal iniciada a partir de mediados de la década del setenta como resultado del fin de los "años dorados" del capitalismo ha sido devastadora para los países periféricos. Mientras que los países centrales han concentrado el progreso técnico y el desarrollo de la investigación, en los países periféricos se verifica una mayor vulnerabilidad económica junto con una profunda crisis social que implica un creciente desempleo, subempleo, pobreza, indigencia y exclusión social.

Hasta el BM, frenético defensor de las recetas neoliberales globales, y la United Nations Conference on Trade and Development (Unctad) (2004) estiman que si persisten las tendencias anteriormente planteadas aumentará el número de personas que viven en condiciones de extrema pobreza en los países menos adelantados, pasando de 334 millones en el 2000 a 471 millones en el 2015. 
Respecto al crecimiento económico de México, no cabe duda de que este ha registrado altibajos desde la puesta en marcha del llamado modelo neoliberal y cómo el poco, nulo o negativo crecimiento del PIB ha acentuado las desigualdades espaciales, sectoriales y sociales.

La política económica ${ }^{2}$ en general aplicada para reactivar el modelo de crecimiento económico de México ha manifestado en su interior contradicciones en sus estrategias y políticas aplicadas desde una política monetaria recesiva que en lugar de reactivar el crecimiento económico, este se ha venido a la baja, al grado de no garantizar al menos en términos compensatorios el hecho de "aliviar los extremos de pobreza" que experimenta el país.

Durante la década de los ochenta, el FMI y el BM recomendaron a los países en desarrollo la aplicación de políticas de estabilización, primero, y ajuste estructural, después. Respecto a los programas de ajuste estructural, estos son la condición impuesta por el FMI o el BM a un país para otorgarle respaldo financiero destinado a afrontar un grave problema de pagos internacionales. Los programas de ajuste estructural (PAE) surgieron a comienzos de 1980, como respuesta a la crisis de la deuda externa de los países en desarrollo. Los PAE obedecen a una concepción extremadamente ortodoxa de la política económica, que años más tarde sería bautizada por sus propios impulsores como el Consenso de Washington.

El Consenso de Washington surgió en 1989, con el fin de procurar un modelo más estable, abierto y liberalizado para los países de América Latina. Sin embargo, a mediados de la década de los noventa la viabilidad del conjunto de políticas y de las propuestas neoliberales del Consenso de Washington empezó a mostrar signos de desgaste.

2 Por política económica debe de entenderse, acorde a Fernández, Parejo y Rodríguez (1995), como aquella que describe el proceso mediante el cual el Gobierno, a la luz de sus fines políticos generales, establece la importancia relativa de ciertos objetivos, utilizando, si es preciso, instrumentos o cambios institucionales en su intento por conseguir aquellos objetivos. La política económica representa, de alguna manera, las acciones del Gobierno y otros órganos representativos del Estado para alcanzar ciertos fines de interés general.
En 1996, el propio Williamson reconoció las limitaciones del decálogo de reformas y reclamó reformas "de segunda generación" que corrigieran el sesgo neoliberal del primer consenso. Los principales componentes del paquete de reformas reflejadas desde su inicio, como es la estabilización macroeconómica, equilibrios fiscales y liberalización de los mercados, siguen teniendo un lugar central dentro de la nueva propuesta.

El mismo vicepresidente senior y economista en jefe del BM, Stiglitz (2002), hace una crítica respecto al desempeño de los organismos internacionales o llamadas también instituciones financieras (FMI, BM) que operan con los fundamentos de la teoría o modelo neoliberal; ${ }^{3}$ estos se constituyen en los pilares de la política económica ${ }^{4}$ de muchos países.

En efecto, desde la década de los setenta, y hasta el día de hoy, la economía de los países desarrollados ha estado dominada por el enfoque neoclásico, equivalente a su ideología práctica al neoliberalismo, donde los operadores mundiales son los dos organismos financieros (FMI y BM) que sustentan el liderazgo de los Estados Unidos. ${ }^{5}$ Sin

3 El enfoque neoliberal se fundamenta en cinco pilares básicos: liberalización del comercio exterior, liberalización del sistema financiero, la reforma del Estado, la reforma del mercado de trabajo y la atracción de capitales extranjeros. En la década de los ochenta, tanto el FMI como el BM recomendaron a los países subdesarrollados la aplicación secuencial de una política de estabilización seguida de una de ajuste estructural. Como lo explica Ffrech (2005, p. 78). “EI enfoque neoliberal, tiende a efectuar reformas de manera abrupta y extrema, dando por supuesto que los mercados se tornan complejos espontáneamente al liberalizarse; ese enfoque acostumbra a no considerar interrelaciones claves entre variables y se caracteriza por su cortoplacismo. De ello resulta que los procesos de ajuste neoliberal tiene a generar más perdedores que ganadores, con efectos regresivos ante los shock externos y los programas antiinflacionarios de unianclaje (por ejemplo, conseguido mediante la fijación del tipo de cambio o por su apreciación real, o bien por una política monetaria contractiva)".

4 Los préstamos condicionados suponen una injerencia en la política de los países pobres: otorgo un préstamo, si se aplica una política que yo (FMI) elaboro. Esas políticas, planes de ajuste estructural, consisten esencialmente en liberalizar los mercados en el interior, aplicar políticas (fiscal, monetaria) restrictivas, apertura externa (liberalización externa -apertura del capital extranjero, aumento de las exportaciones y reducción de las trabas arancelarias a las importaciones-).

5 ¿Por qué son tan controvertidas las recomendaciones y decisiones del fondo? En primer lugar, porque en este tienen más capacidad de decisión los que más dinero aportan, o 
embargo, a pesar de la serie de fracasos que han experimentado los países latinoamericanos, sus Gobiernos de corte neoliberal todavía siguen creyendo en las bondades del llamado trickle effect (el goteo), el cual postula que el crecimiento acaba beneficiando también a los de abajo porque gotea a través de mayores empleos, ingresos y posibilidades de consumo. Intervienen aquí los propagandistas vernáculos del neoliberalismo que no dudaron en valerse de un truco y simplemente modificaron el nombre del efecto: en vez de "goteo" pasaron a hablar de "derrame", donde basta solo un aumento sostenido del producto para derramar las mieles sobre la sociedad en su conjunto y hará a todos felices. En el plano retórico, fue una maniobra eficaz, a nivel de los resultados concretos; ya se sabe lo que sucedió y lo que está sucediendo.

El economista Guillén (2005) expone que la versión más radical de la tesis de la globalización afirma que las economías nacionales fueron simplemente incorporadas a los mercados mundiales y que el poder de las fuerzas del mercado anula o vuelve innecesaria cualquier posibilidad de gestión pública eficiente, sea por los Estado-nación, acuerdos internacionales o instituciones supranacionales. En esa condiciones, la recomendación que se impone es adoptar políticas amistosas para los mercados, es decir, políticas funcionales para los intereses de las clases dominantes, como son las políticas neoliberales del Consenso de Washington. ${ }^{6}$

sea, los países más ricos: no hay criterios democráticos en la toma de decisiones (casi siempre se hace lo que dice el grupo de los siete países más industrializados, que se ven previamente a las reuniones del fondo). Así, para tomar decisiones importantes, es necesario el $85 \%$ de los votos, pero Estados Unidos tiene aproximadamente el $18 \%$, con lo cual un solo país puede bloquear cualquier decisión.

6 "La llamada condicionalidad estructural, forma dominante de imponer políticas consensuadas en Washington. La política de condicionalidad estructural llevada a cabo por instituciones financieras internacionales es criticada por poner en tela la soberanía y el albedrío de países para determinar su futuro. Las exigencias impuestas por dichas instituciones, a cambio de financiamientos para el desarrollo, a menudo se utilizan como pretexto para ocultar responsabilidades de gobiernos en fracasos económicos. Los estudios revisados apuntan que la condicionalidad fue más efectiva cuando se limitó a pocos elementos vinculados al macro desempeño de los países y en la medida que los programas fueron tomados como propios por los gobiernos (apoderados o tomados en propiedad), con cierta dosis de flexibilidad que permitió
Es a través de los mercados financieros globalizados ${ }^{7}$ y desreglamentados como estos se erigen en auténticos jueces de las políticas económicas de los Gobiernos. Estos últimos, como dice Aldo Ferrer, deben "satisfacer las expectativas de los mercados con políticas alineadas con los criterios neoliberales" (citado en Guillén, 2005, p. 42).

En fin, los mercados financieros ejercerían una auténtica dictadura (la famosa "tiranía de los mercados"), que reduciría la autonomía de la política económica con todos los riesgos que ello implica para la democracia. Sin embargo, no hay que dejar de lado que la decisión de abrir las economías en el terreno comercial y financiero fue tomada por los Estados nacionales bajo la presión de los organismos internacionales.

En términos generales, la abrupta apertura de fronteras y la abolición del proteccionismo, sin el armazón institucional apropiado, han desencadenado menor desarrollo económico, deterioro social y descrédito de la democracia, como lo describe Ibarra (2004).

Específicamente, uno de los documentos que evalúa el pobre desempeño de la economía mexicana es el que realiza la Iniciativa para la Revisión Participativa de las Políticas de Ajuste Estructural (Sapri, 2002), ${ }^{8}$ que estudia cómo las políticas de ajuste $^{9}$ que fueron frecuentemente identificadas

incluir especificidades de las economías y las sociedades en las cuales se aplicaron" (Mañan, 2004, p. 34).

7 "El proceso de globalización financiera se explica por la regla de las tres D: Descompartimiento abolición de las fronteras entre los mercados, apertura hacia el exterior de los mercados nacionales; Desreglamentación (abolición de la reglamentación de cambios a fin de facilitar la circulación internacional de capital) y Desintermediación —disminución de la parte de financiamiento que transita por los intermediarios financieros en beneficio de las finanzas directas-" (Guillén, 2005, pp. 104-107).

8 La Iniciativa para la Revisión Participativa de las Políticas de Ajuste Estructural es una investigación sobre los efectos de políticas específicas del ajuste estructural en una amplia gama de sectores económicos y sociales, como de grupos de la población.

9 En efecto, los programas de ajuste estructural han sido objeto de muy variadas críticas por los efectos nocivos que producen sobre las economías en las que se vienen aplicando. Incluso se han generado críticas que provienen de las mismas instituciones internacionales, como Unicef (1987) Cornia et al. (1987) o la propia Comisión Económica para América Latina y el Caribe (Cepal) (1996), que discrepan con el FMI y el BM sobre los objetivos prioritarios y los medios 
y exploradas, como son la apertura comercial, la liberalización del sector financiero, la privatización, la reforma al mercado de trabajo, las reformas a los sectores agropecuario y minero, y la reforma a la política de gasto público, han contribuido a un mayor empobrecimiento y marginación de las población mexicana.

Después de un tiempo de aplicación neoliberal, las políticas macroeconómicas para el crecimiento sostenido del producto nacional y del empleo han sido cuestionadas debido a que se le ha otorgado más importancia a la creación de un marco de "estabilidad macroeconómica", entendida esta última linealmente con inflación decreciente, próxima al nivel inflacionario de los Estados Unidos y finanzas públicas equilibras o cercanas al ingreso-gasto ${ }^{10}$ (Calva, 2007).

En otras palabras, como lo explica Chávez (2007), la falta de crecimiento se debe al carácter secuencial de las políticas impuestas, las cuales consideran que primero tiene que consolidarse la estabilidad macro, después logar la expansión productiva y luego distribuir socialmente los beneficios. Sin embargo, los instrumentos empleados para bajar los precios (restricción monetaria, fiscal y salarial, el uso de la paridad como "ancla" desinflacionaria, la menor intervención estatal, la desregulación interna y la apertura comercial y financiera) explican la pérdida del crecimiento.

Así pues, se pueden resumir en dos puntos generales los efectos del proyecto neoliberal promovido por el FMI, el BM, el Consenso Washington y los Gobiernos locales (Chávez, 2001):

1. Las políticas de estabilización instrumentadas hasta el momento no han resuelto

por utilizar. La propia Unicef publicó un estudio en 1987 con el título de "Ajuste con rostro humano", que contiene una crítica demoledora sobre los efectos negativos que los programas de ajuste estructural tienen sobre los sectores sociales más pobres. Dicho estudio sostiene que el ajuste no restablece el crecimiento, que es imprescindible incorporar la dimensión humana.

10 La estrategia de rígidas metas de balance ingreso-gasto público fue fundamentalmente mantenida durante el Gobierno de Ernesto Zedillo. Recortes del gasto público, el balance fiscal operacional arrojó un déficit de apenas $0,4 \%$ del PIB en su Gobierno. el dilema fundamental de la región, como afianzar la estabilidad interna, sin sacrificar el crecimiento, el bienestar social y el equilibrio de las cuentas externas. Todos los indicadores económicos se han subordinado a la meta de hacer converger la inflación local a la internacional. Sin haber alcanzado todavía el objetivo, tales medidas han forzado a nuestros países al estancamiento, crisis devaluatorias y balanzas de pagos que se tornan cada vez más deficitarias, hecho que agrava los problemas que esas políticas pretenden resolver.

2. Los costos sociopolíticos asociados a la naturaleza excluyente de las políticas estabilizadoras y las reformas estructurales, en su mayor parte evitables, que se sintetizan en la peligrosa desigualdad social, en el alarmante aumento del número de personas hundidas en la pobreza y la miseria extrema.

Por ejemplo, la tabla 1 refleja una caída en el crecimiento, pues, contrastando los datos de 1959-1982, la tasa media real anual del PIB es de $6,1 \%$ y del per cápita de 2,3\%; por el contrario, en $1983-2012$ se registra un $2,5 \%$ y un $1,3 \%$, respectivamente.

En cuanto a la demanda local, esta perdió impulso, de 1959 a 1982 el consumo privado creció 5,0\% y el público, 12,8\%; mientras que de 1982 a 2012 en los mismos rubros se registra una caída del orden de $2,3 \%$ y $1,2 \%$, respectivamente. En los mismo años, de 1959 a 1982, la formación bruta de capital fijo en el sector privado creció $6,8 \%$ y el público, 9,0\%; en cambio, entre 1983-2012, creció solo $2,5 \%$ y $-1,1 \%$ en cada caso (tabla 1 ).

De acuerdo con Inegi (Unité con datos de Inegi), en el 2013 el crecimiento de la economía (PIB) se ubicó en 1,06\%, el peor desempeño de la última década salvo en el nefasto 2009 (-4,70\% del PIB); con ello, la tasa media de crecimiento anual (TMCA) del último quinquenio (2009-2013) se ubica en únicamente $1,81 \%$. 
Tabla 1.

Variables macroeconómicas

\begin{tabular}{|c|c|c|c|}
\hline \multicolumn{2}{|c|}{$1959-1982$} & \multicolumn{2}{c|}{$1983-2012$} \\
\hline Tasa media real anual del PIB & Tasa per cápita del PIB & Tasa media real anual del PIB & Tasa per cápita del PIB \\
\hline $6,10 \%$ & $2,30 \%$ & $2,20 \%$ & $1,10 \%$ \\
\hline Consumo privado & Consumo público & Consumo privado & Consumo público \\
\hline $5,90 \%$ & $12,80 \%$ & $2,30 \%$ & $1,20 \%$ \\
\hline $\begin{array}{c}\text { Formación de capital fijo } \\
\text { privado }\end{array}$ & $\begin{array}{c}\text { Formación de capital fijo } \\
\text { público }\end{array}$ & $\begin{array}{c}\text { Formación de capital fijo } \\
\text { privado }\end{array}$ & $\begin{array}{c}\text { Formación de capital fijo } \\
\text { público }\end{array}$ \\
\hline $6,80 \%$ & $9,00 \%$ & $2,50 \%$ & $-1,10 \%$ \\
\hline
\end{tabular}

Fuente: elaboración del autor a partir de datos del Inegi y Banco de México, varios informes.

Por supuesto, la pérdida del mercado interno como impulsor del crecimiento fue deliberado, pues se buscó sustituirlo por las exportaciones. Los indicadores confirman lo dicho, ya que las exportaciones se multiplican por nueve de 1982 a 2006 (Merchand, 2007). ${ }^{11}$ Sin embargo, este coeficiente exportador no se reflejó en el crecimiento interno, puesto que el grueso de las exportaciones no se manifiesta en un alto valor agregado y se concentran solo en unos cuantos sectores y productos controlados por los corporativos transnacionales.

No obstante que las estrategias macroeconómicas desplegadas por el Gobierno mexicano desde hace 25 años han redundado en un deterioro económico y social de los mexicanos, se sigue defiendo el concepto de la estabilidad macroeconómica que se sustenta en mantener una política económica anclada en políticas monetarias y fiscales restrictivas de carácter procíclico (Guillén, 2007). ${ }^{12}$ La política procíclica incide por supuesto

11 La cuestión es que la evolución, tanto de las exportaciones como de las importaciones, demuestra que el incremento considerable de las exportaciones se debe a un explosivo incremento de las importaciones, esto es, exportamos lo que con anterioridad importábamos (Merchand, 2007).

12 Las políticas procíclicas agudizan la recesión, principalmente una política monetaria contraccionista, esto es, el incremento una y otra vez del corto monetario; cuando ya estamos en pleno ciclo recesivo, también se aplica una política fiscal contraccionista, pues si hay recesión caen los ingresos y si hay metas fiscales fijas lo que se hace es recortar el gasto. Mientras los países industrializados aplican políticas fiscales y monetarias expansivas (contracíclicas) para apun- en la política cambiaria de "flotación administrada" de la moneda que provoca la apreciación persistente del peso y alienta la especulación financiera y bursátil. Respecto a los efectos de esta política procíclica (monetaria restrictiva) ${ }^{13}$ en los salarios, se mantiene la práctica nociva de fijar los aumentos de salarios en función de la inflación esperada y no de la pasada (Calva, 2007; Huerta, 2004; Guillén, 2007; Chávez, 2007).

En efecto, la política monetaria restrictiva con objetivos antiinflacionarios forma parte del recetario del Consenso de Washington; esta ha sido una condición para atraer flujos privados de capital del exterior, y como consecuencia ha favorecido al capital financiero internacional y la concentración del ingreso en unos cuantos rentistas nacionales y extranjeros.

Como lo reafirma de nuevo Calva (2007), las estrategias macroeconómicas que fundan la

talar su crecimiento en caso de recesión o desaceleración de sus economías (incurriendo entonces en elevados déficit fiscales y en posturas monetarias expansivas), la receta que el FMI prescribe a los países en desarrollo es exactamente la contraria: austeridad fiscal y "disciplina" monetaria, aunque nuestras economías se hundan en profundas recesiones o en prolongados estancamientos. México mantiene políticas monetarias y fiscales restrictivas para seguir priorizando la baja de la inflación, a costa de seguir relegando el crecimiento económico.

13 La política monetaria se vuelve pasiva o "acomodaticia" y se reduce a controlar y regular los réditos y las operaciones de mercado abierto. Las tasas de interés locales deben converger con las foráneas ("ley de precio único"), a medida que se reduzca la inflación y no cambie la tasa de devaluación (Chávez, 2007). 
estabilidad de los precios en objetivo prioritario a ultranza, utilizando el tipo de cambio como ancla antiinflacionario, altas tasas de interés y rígidas políticas de austeridad fiscal, resultan eficaces para estabilizar los precios, pero desestabilizan el crecimiento del PIB y del empleo, con lo cual se disparan altísimos costos en términos de recorte en las capacidades productivas.

Una de las formas como se manifiesta la pérdida en las capacidades productivas internas se traduce en un coeficiente de importaciones que ha crecido exponencialmente, sin que el desempeño de las exportaciones por muy dinámico que este sea tienda a igualarse con el de las importaciones. Si a este desequilibrio externo creciente se le suma el servicio de la deuda, se tiene como efecto una combinación perniciosa de políticas contraccionistas que generan un círculo vicioso que retroalimenta dependencia, fragilidad y subordinación extrema del exterior (sobre todo dependencia estructural con el mercado estadounidense).

En otro artículo, Huerta (2006) explica que si bien se ha alcanzado estabilidad a través de evidenciar altos niveles de apreciación cambiaria en los últimos años en México, esto se ha logrado por la entrada de capitales, estimulada por el proceso de privatización y extranjerización de la economía. Otro factor que ha ayudado fuertemente a confiar en la estabilidad económica del país y que asegura beneficios extraordinarios para el capital privado es la disminución persistente de los salarios reales.

Específicamente, al contar con un tipo de cambio sobrevaluado y salarios en continua caída, ${ }^{14}$ se compromete la dinámica de acumulación nacional y se genera una trayectoria de estancamiento. La

14 Los trabajadores mexicanos son los peor pagados de todos los países miembros de la Organización para la Cooperación y el Desarrollo Económicos (OCDE). Según datos de la institución correspondientes a 2002, el salario promedio en el sector manufacturero mexicano es entre 2,5 y 3 dólares por hora, muy por debajo del promedio de la OCDE (15 dólares) y una décima parte de lo que se paga en Noruega (28 dólares). Los sueldos en las fábricas de México son similares a los de Brasil, y ambos son superiores a los que se pagan en India y China. En 36 años el poder adquisitivo del salario mínimo acumuló una pérdida de $72,8 \%$; es decir, el sueldo tiene ahora solo una cuarta parte del valor de 1976 , advirtió la Secretaría del Trabajo y Previsión Social (STPS). apreciación del tipo de cambio lleva a una reducción de la demanda por exportaciones y a un aumento de las importaciones, mitigándose las presiones de la demanda agregada sobre los precios internos. La apreciación real del tipo de cambio incide negativamente sobre la competitividad-precio de los productos mexicanos, con el consiguiente efecto negativo sobre el crecimiento económico.

Por ejemplo, el indicador que muestra fehacientemente el fracaso del modelo neoliberal mexicano es, sin lugar a dudas, lo que respecta al rubro de las distribuciones del ingreso que se ha agravado en este cuarto de siglo (Ayala, 2007a). En contraste, Nadal (2001) explica que existen tantas alternativas de política económica como segmentos de la población se quiera atender y cuyo bienestar se busca mejorar. El dilema consiste en si beneficia a una élite que representa apenas el $10 \%$ de la población o en cambio se busca mejorar el nivel de vida y bienestar del $90 \%$ de la población restante. La primera opción es la que representa la población objetivo del modelo neoliberal.

De acuerdo con cuentas nacionales, en el rubro correspondiente al ingreso nacional disponible se tienen dos grandes componentes que indican la porción del ingreso nacional que va a la población trabajadora (remuneraciones a asalariados) y la que va a las empresas (excedente de operación). De hecho, en los países desarrollados, las remuneraciones al trabajo representan entre el $50 \%$ y el $60 \%$ del producto interno bruto (PIB): desde el $50,5 \%$ en Canadá o el 51,8\% en Japón, hasta el 57,1\% en Estados Unidos o el 61,6\% en Suiza; en México tales remuneraciones solo representan el 30,4\% del PIB. Si la comparación se hace con el ingreso nacional disponible, el contraste es aún más marcado, ya que las remuneraciones al trabajo en los países avanzados representan entre el $60 \%$ y el $70 \%$ de este ingreso, mientras que en México, únicamente el $33,4 \%$ (tabla 2).

De igual forma, y como contrapartida, el excedente de operación (la utilidad bruta de las empresas) oscila en general entre el $30 \%$ y el $40 \%$ del PIB o entre el $35 \%$ y el $45 \%$ del ingreso nacional en las economías avanzadas, muy por debajo del $59 \%$ 
Tabla 2 .

Distribución del ingreso entre trabajo y capital

\begin{tabular}{|c|c|c|c|c|}
\hline & \multicolumn{2}{|c|}{ Remuneraciones al trabajo } & \multicolumn{2}{c|}{ Excedente bruto de operación } \\
\hline Clemania & 51 & $\begin{array}{c}\text { Como \% ingreso nacional } \\
\text { disponible }\end{array}$ & Como \% PIB & $\begin{array}{c}\text { Como \% ingreso nacional } \\
\text { disponible }\end{array}$ \\
\hline Canadá & 50 & 61 & 38 & 45 \\
\hline Estados Unidos & 57 & 59 & 38 & 45 \\
\hline Francia & 52 & 65 & 35 & 40 \\
\hline Japón & 51 & 60 & 40 & 59 \\
\hline México & 30 & 64 & 59 & 65 \\
\hline Reino Unido & 55 & 33 & 32 & 35 \\
\hline Suecia & 56 & 61 & 29 & 35 \\
\hline Suiza & 62 & 54 & 35 & 40 \\
\hline
\end{tabular}

Fuente: elaboración del autor a partir de datos de Ayala (2007a).

y el $65 \%$ que, respectivamente, se apropian en la economía mexicana.

Cabe destacar que en México (gráfica 1) las remuneraciones al trabajo mostraban hace tres décadas una tendencia uniforme, aunque leve, como proporción del ingreso nacional, desde el 38,1\% de
1970 hasta el 43,5\% de 1976. Dicha tendencia se estanca hasta 1982 en el 41,6\%) y desde ahí inicia una regresión hasta la participación mencionada del $33,4 \%$ en 2004; esto es, aproximadamente la mitad de lo que el trabajo percibe en un país desarrollado y más igualitario (Ayala, 2007a).

Gráfica 1 .

Asignación porcentual del ingreso nacional disponible 1970-2004

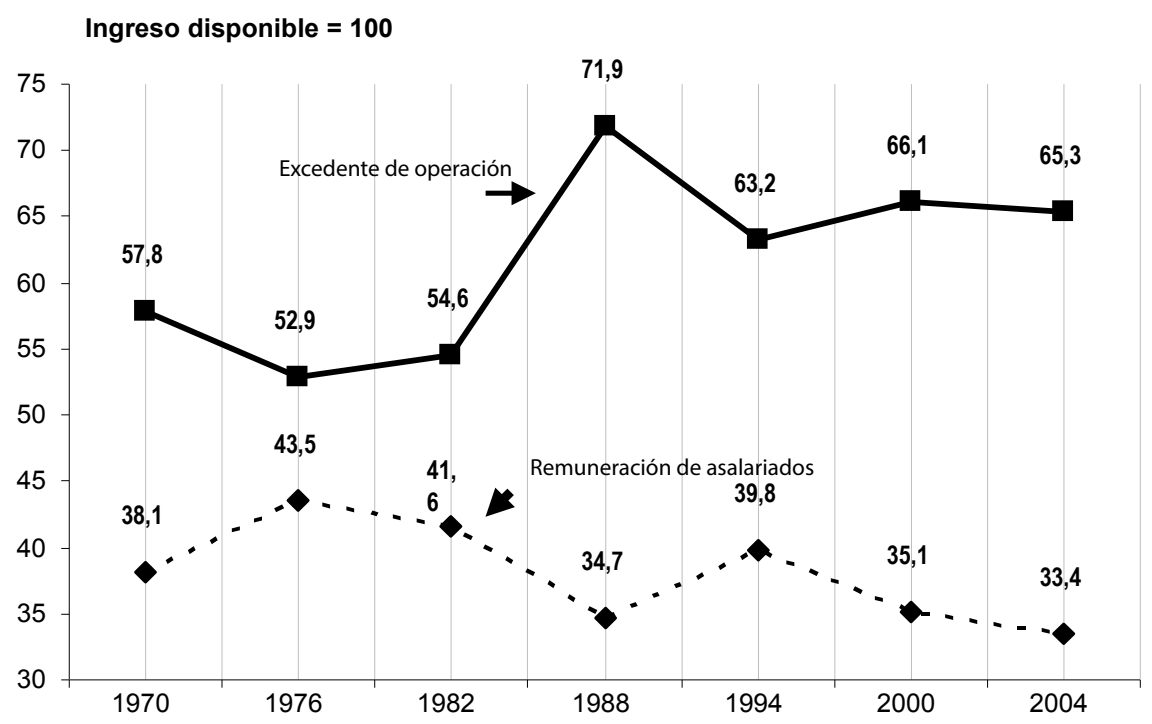

Fuente: elaboración del autor a partir de datos de Ayala (2007). 
Impuesto sobre la renta (tasas marginales máximas al ingreso personal), 1975-2012

\begin{tabular}{|c|c|c|c|c|c|c|c|c|c|c|c|c|}
\hline \multicolumn{13}{|c|}{ Tasa de impuesto sobre la renta (\%) } \\
\hline & 1975 & 1980 & 1985 & 1990 & 1995 & 2000 & 2002 & 2004 & 2006 & 2008 & 2010 & 2012 \\
\hline Alemania & 56 & 56 & 56 & 53 & 53,8 & 53,8 & 51,2 & 47,5 & 44,3 & 47,5 & 47,5 & 47,5 \\
\hline Australia & 65 & 61,5 & 60 & 48 & 47 & 48,5 & 48,5 & 48,5 & 48,5 & 46,5 & 46,5 & 47,5 \\
\hline Austria & 62 & 62 & 62 & 50 & 50 & 50 & 50 & 50 & 50 & 50 & 50 & 50 \\
\hline Bélgica & 60 & 76,3 & 71,6 & 55 & 55 & 63,9 & 55,6 & 53,5 & 53,5 & 53,7 & 53,7 & 53,7 \\
\hline Canadá & 47 & 61 & 34 & 29 & 46,4 & 46,4 & 46,4 & 46,4 & 46,4 & 46,4 & 46,4 & 48 \\
\hline Dinamarca & 40 & 66 & 39,6 & 68 & 63,1 & 59,7 & 54,4 & 59,7 & 59,7 & 59,7 & 52,2 & 60,2 \\
\hline $\begin{array}{l}\text { Estados } \\
\text { Unidos }\end{array}$ & 70 & 70 & 50 & 28 & 39,6 & 46,7 & 45,2 & 41,5 & 41,4 & 41,9 & 41,9 & 41,9 \\
\hline España & 62 & 65,5 & 66 & 56 & 56 & 48 & 49 & 45 & 45 & 43 & 43 & 52 \\
\hline Finlandia & 51 & 51 & 51 & 43 & 39 & 55,2 & 53,2 & 52,1 & 50,9 & 50 & 49 & 49 \\
\hline Francia & 60 & 60 & 65 & 51,8 & & 58,3 & 57,8 & 53,4 & 53,5 & 45,8 & 46,7 & 50,7 \\
\hline Irlanda & 77 & 60 & 65 & 56 & 48 & 44 & 42 & 42 & 42 & 41 & 47 & 48 \\
\hline Italia & 72 & 72 & 65 & 50 & 51 & 46,4 & 46,1 & 46,1 & 44,6 & 44,9 & 45,2 & 48,6 \\
\hline Japón & 75 & 93 & 70 & 50 & 50 & 50 & 50 & 50 & 50 & 50 & 50 & 50 \\
\hline México & & 55 & 55 & 35 & 35 & 40 & 35 & 33 & 29 & 28 & 30 & 30 \\
\hline Noruega & 73 & 75,4 & 40 & 17 & 13,7 & 47,5 & 47,5 & 47,5 & 40 & 40 & 40 & 40 \\
\hline Países Bajos & 71 & 72 & 72 & 60 & 60 & 60 & 52 & 52 & 52 & 52 & 52 & 52 \\
\hline Portugal & & 80 & 60 & 40 & 40 & 40 & 40 & 40 & 42 & 42 & 45,9 & 49 \\
\hline R. Unido & 83 & 83 & 60 & 40 & 40 & 40 & 40 & 40 & 40 & 40 & 50 & 50 \\
\hline Suecia & 87 & 86,5 & 80 & 65 & 30 & 55,4 & 55,5 & 56,5 & 56,6 & 56,4 & 56,6 & 56,6 \\
\hline Suiza & 44 & 41 & 11,5 & 11,5 & 11,5 & 43,2 & 38,4 & 42,1 & 42,1 & 41,7 & 41,7 & 41,7 \\
\hline Prom. * & 64,2 & 66,1 & 56,8 & 45,9 & 43,1 & 50,4 & 48,6 & 48,1 & 47,1 & 47 & 47,6 & 49,3 \\
\hline
\end{tabular}

* Promedio de 25 países, sin incluir a México.

Fuente: elaboración del autor a partir de World tax Database, office of tax policy research http://www.oecd.org-policy/Tablepolicy/T\%201.7_Mar2013.xlsx

Otro rubro (tabla 3 y gráfica 2 ) que muestra el mecanismo redistributivo principal de las economías de mercado es el impuesto sobre la renta (ISR). En el caso de México con respecto a otras naciones, se registra de un $30 \%$ a $35 \%$ la tasa máxima del ISR para los altos ingresos personales, cuando las 20 economías más avanzadas aplican una tasa promedio de $49 \%$, y al mantener el ISR a las utilidades de las empresas en $30 \%$, cuando en países como Estados Unidos y Japón aplican una tasa del $40 \%$. Estos porcentajes sobre el ISR indican que no se cobran los impuestos correspondientes al $1 \%$ más privilegiado, ni a los corporativos de empresas nacionales y extranjeras (Ayala, 2014). ${ }^{15}$

15 Debido a los estímulos fiscales, impuestos especiales y beneficios tributarios a las empresas, durante el 2012 (último año de la administración de Felipe Calderón Hinojosa) el fisco dejó de recibir $\$ 769.448 .000$ millones. Tal cifra representó la mitad de la recaudación total, que ascendió a $\$ 1.516 .950 .000 .000$. La auditoría demostró que en 2012 el Gobierno calderonista dejó de percibir por recaudación fiscal $\$ 769.448 .000$ millones; de ellos, \$235.177 correspondieron a IVA; \$176.890, a impuestos especiales; \$ 143.318, al ISR empresarial; \$128,786, al ISR a personas físicas; $\$ 73.00015$ millones al IETU, y \$12.262, a estímulos fiscales (ver http:// www.jornada.unam.mx/2014/02/21/politica/005n2pol). 
Gráfica 2.

Tasas máximas al ingreso personal (1975-2012). Porcentaje de impuestos a los altos ingresos en países seleccionados

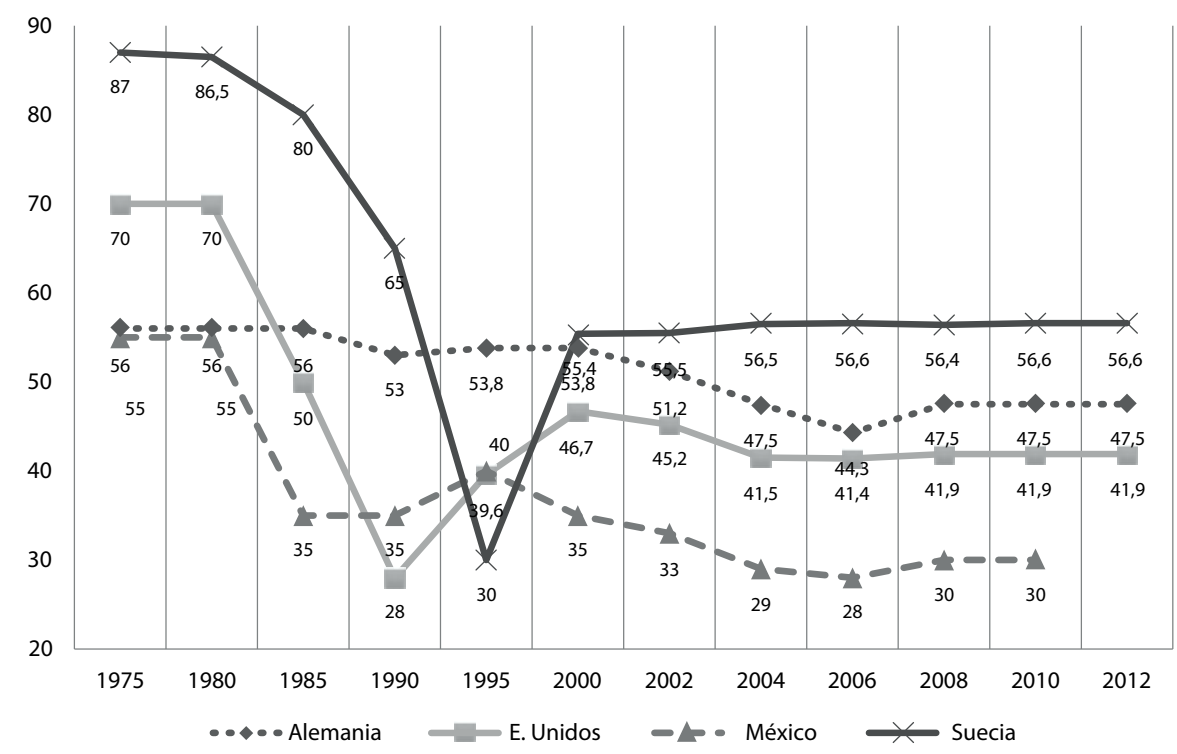

Fuente: elaboración del autor.

También se señala que el mecanismo redistributivo principal de las economías de mercado es el impuesto sobre la renta (ISR). Esto confirma, con otros datos, lo que señala Oxfam (2014): la inequidad distributiva del ingreso en México y otras partes del mundo con cifras que muestran la concentración mundial de la riqueza; en otras palabras, la concentración de los ingresos y la riqueza dificulta la representación política de las clases desfavorecidas a costa de beneficiar a las clases acaudaladas.

Hay que aclarar que no hay país que no presente concentración de ingreso y riqueza en torno a las clases acaudaladas y corporativos financieros, ${ }^{16}$

16 "Un grupo de inversionistas cuyo número equivale a 0,18 por ciento de la población del país concentró inversiones en el mercado accionario por un monto que equivale a 42 por ciento de la riqueza nacional, proporción que ha ido creciendo de manera constante en la última década. En conjunto de 33 casas de bolsa que operan en el país tiene bajo su custodia activos de 206 mil 315 inversionistas ( 0.18 por ciento de la población) por un monto de 6 billones 802 mil 875 millones de pesos, cantidad superior en 6.7 por ciento a la de un año antes, informó la Comisión Nacional Bancaria (CNBV). La cantidad de activos en poder de este grupo de comerciales y tecnológicamente dominantes. Sin embargo, existen diferencias notables entre las naciones avanzadas y atrasadas; en las primeras se aplican políticas y mecanismos efectivos para redistribuir el ingreso con mayor equidad entre el capital, el trabajo y los grupos de la población por el otro (Ayala, 2007b).

Insistiendo, ¿qué tan grave será la concentración del ingreso en los países en desarrollo, que hasta los organismos, como el FMI y el BM, piezas clave en la instrumentación del neoliberalismo, ahora aparecen como críticos de lo que ellos mismos propiciaron ${ }^{17}$ Por ejemplo, en el reporte

inversionistas es equivalente a 42 por ciento del valor de la economía mexicana, medido a través producto interno bruto, que ronda los 16 billones de pesos, de acuerdo con datos preliminares de la Secretaría de Hacienda y Crédito Público contenidos en los criterios generales de política económica 2014" (González, 2014).

17 Los propios organismos internacionales reconocen que las políticas de ajuste han generado pérdidas entre los pobres. De hecho, la relación entre los programas de ajuste y el crecimiento de la pobreza y la desigualdad es lo que condujo al presidente del BM (Jim Wolfensohn) a aceptar el desafío de las organizaciones no gubernamentales y a poner en 
sobre perspectivas de la economía mundial del FMI (octubre 2007), el organismo asienta:

En los pasados 20 años, la desigualdad del ingreso ha aumentado en la mayoría de los países y regiones [...]; (si bien) el ingreso per cápita se ha incrementado en casi todas las regiones incluso para los segmentos más pobres de la población [...] los ingresos de los grupos relativamente acomodados han aumentado a un ritmo más rápido. Los avances tecnológicos son el factor que más ha contribuido al aumento reciente de la desigualdad [...] la globalización financiera (y la inversión extranjera directa, en particular) también han contribuido a aumentar la desigualdad [...].

De la misma manera, el BM expresa que la lenta reducción de la tasa de pobreza se debe atribuir a que no hay un incremento suficiente en el PIB anual. ${ }^{18} \mathrm{~A}$ más de diez años de la firma del TLCAN, los resultados de la integración han sido más complejos y contradictorios que los esperados. La heterogeneidad estructural, rasgo peculiar de la economía mexicana, en lugar de atenuarse se ha acrecentado entre un sector "moderno" y otro "atrasado". La economía mexicana muestra ya fallas estructurales en la creación de empleos en el sector formal, impulsando con gran fuerza

marcha la investigación Saprin (2002). Sin embargo, el propio BM insiste en que las ganancias macroeconómicas obtenidas a partir de la ejecución de las políticas de ajuste compensan cualquier pérdida a corto plazo entre ciertos grupos y sectores de la población, porque ponen a los países en la senda hacia el crecimiento sostenible.

18 Esta visualización de enfocar el desarrollo como un resultado de un indicador del producto per cápita, o por un crecimiento en los índices de valor de la producción de bienes y servicios, ha sido muy cuestionada. Stiglitz, $J$ (2003), explica que las tan mencionadas mediciones en torno al Producto Interno Bruto (PIB) no dan cuenta de la complejidad del panorama económico. Este coeficiente (PIB) debería reemplazarse por el "Ingreso Nacional Neto", una medida que apunta al bienestar futuro de los ciudadanos porque incluiría para su cuantificación la depreciación de los recursos físicos del país y el agotamiento de los recursos naturales, la degradación del medio ambiente, la venta de los activos nacionales en el exterior, el agravamiento de la sensación de inseguridad y vulnerabilidad económicos, etc. la emigración de trabajadores hacia el exterior, así como el crecimiento sin precedentes de la economía informal y el incremento de los índices de pobreza.

Respecto al rubro del desempleo, en el segundo trimestre de 2010, la población desempleada en el país fue de 2,5 millones de personas, la tasa de desocupación se incrementó en un 4,4\% en el 2010, considerando que en el 2006 la tasa de desocupación registrada fue de un 2,8\% (Inegi, 2010).

La población que labora en el sector informal se incrementó en 23,6 millones de personas en el periodo abril-junio de 2010; la población ocupada en el sector informal participa con un $42,8 \%$ de la población total ocupada, tanto en el sector formal como informal (Encuesta Nacional de Ocupación y Empleo [ENOE], 2010). No obstante, los datos que maneja la Secretaría del Trabajo y Previsión Social (STPS) en un documento publicado en el Diario Oficial de la Federación de 2013, las cifras se disparan, pues el alto grado de ocupación informal en el país es ahora de 29,3 millones de trabajadores que están en esa condición; es decir, sin protección social para ellos y sus familias. Los trabajadores que se ubican en la informalidad representan ya para el 2013 el 59,1 de la población ocupada; la tasa de ocupación parcial y la desocupación fue de 11,8\%, mientras que la de desempleo se ubicó en $5 \%$.

La pérdida de empleos se presentó en gran medida con las empresas orientadas hacia el mercado interno. Además, la disminución de los salarios reales fue la regla, y la informalización del empleo comenzó a extenderse más. En síntesis, el tipo de desarrollo exportador que la política económica fomenta no se ha traducido en una generación dinámica de empleos formales y remunerativos. De esta manera, en los últimos dos decenios se ha ampliado la brecha laboral entre el sector moderno de la economía y el sector informal, que en una proporción muy elevada es un sector de subsistencia. Las causas estructurales de esta brecha son las mismas que alimentan la expulsión de mano de obra hacia Estados Unidos. Esta es una brecha que refleja la profundización de los fuertes contrastes sectoriales y regionales propios de una estructura 
productiva cada vez más heterogénea, desigual y polarizada como es la mexicana.

\section{EL ESTADO Y LAS DESIGUALDADES REGIONALES}

El postulado que fundamenta este apartado dos sostiene que dadas las propias características históricas del capitalismo y sus mecanismos de expansión este sistema económico reproduce, exponencialmente, cada vez más las brechas económicas y sociales entre regiones nacionales y locales. En otras palabras, el sistema de producción capitalista cuenta con una naturaleza inherente de reproducir desarrollo desigual e incluso es una estrategia que le es propia para poder expandirse en los ámbitos mundiales, nacionales, regionales y locales en los niveles inter e intra. Es decir, el proceso de desarrollo económico capitalista es un proceso desigual, que no afecta de manera uniforme a todas las regiones y países; los patrones de distribución territorial de la actividad económica van a determinar las perspectivas de cada espacio económico.

En otras palabras, el sistema de producción capitalista no es un sistema diseñado para ampliar el bienestar de los habitantes de un país, sus metas son las máximas ganancias y tasas de acumulación. Estas metas son incompatibles con el abuso de bienes y servicios que aumenten el nivel de bienestar.

Las condiciones estructurales donde se ha desenvuelto la economía de México y la de otros países latinoamericanos en iguales condiciones (como en Brasil, Bolivia, etc.) no permiten que sus regiones más atrasadas puedan alcanzar o empatar a otras que muestran una dinámica económica positiva y de mayor participación en los agregados macroeconómicos (producto interior bruto - total o por habitante-, el volumen de población activa y ocupada, productividad media por empleo, el consumo de ingreso por habitante, el nivel de inversión recibida extranjera o nacional, etc.). De la teorización del desarrollo de la década de los cincuenta y sesenta, se desprende la presencia de "trampas de desarrollo". Es posible que exista una configuración de fuerzas que no permita superar un cierto umbral, por encima del cual se entraría en la senda de desarrollo (Ros, 2004).

Por otra parte, el rol que ha jugado el Estado ${ }^{19}$ ha sido fundamental, pues las políticas regionales instrumentadas por este, en lugar de haber aminorado los grados de desigualdad, han sido fomentadas por un desarrollo regional más desequilibrado ${ }^{20}$ y desarticulado en función de los intereses sectoriales (agrícolas, industriales y de servicios), pues solo buscan espacios económicos que permitan reproducir capitales espurios, sin una contribución a las comunidades locales; incluso, muchas de las veces, generan externalidades negativas que socavan el tejido social de los pobladores locales.

Incluso, las disparidades regionales o espaciales tienden a profundizarse cada vez más por la ausencia de una política de desarrollo regional que contemple una estrategia integral orientada a corregir las hondas asimetrías del modelo neoliberal espacial. Si a la falta de una política regional integral o territorial se le suma una reducción de la inversión pública en infraestructura, una contracción del gasto en desarrollo regional (incluso, en el Plan Nacional de Desarrollo 2012-2018 no se encuentra el rubro del desarrollo regional, como estrategia de combate a la pobreza espacial), si también hay una

19 En un trabajo ya clásico de Barkin (1976), se analiza por qué las políticas regionales asociadas a los territorios normalmente han castigado a los pobres de las "regiones ricas" beneficiando a los ricos de las "regiones pobres" (cuestión que obliga al análisis de las desigualdades interregionales), antecedente que obligó a los Gobiernos a focalizar las políticas o los recursos de los fondos de inversión que buscaban resolver el tema de las desigualdades territoriales. Al respecto, Barkin menciona que: "Los programas de desarrollo regional, aunque tengan éxito no necesariamente facilitan o permiten una redistribución del ingreso personal. A menos que se tomen medidas para proporcionar recursos financieros a quienes no los tienen, con limitaciones efectivas para excluir a las elites, los programas de inversión tan solo proporcionaran a los ricos oportunidades posteriores para ampliar el alcance de sus actividades" (1976, pp. 477-501).

20 Los desequilibrios regionales tienen una relación directa con el nivel de competitividad, pues es indudable que los niveles de pobreza y marginalidad afectan de manera negativa la competitividad de los Estados y las regiones. Las regiones con los mayores rezagos económicos deben alcanzar un nivel mínimo de desarrollo en educación, salud e infraestructura para atraer elevados flujos de inversión doméstica y extranjera. 
raquítica generación de empleos (abierto y encubierto), un desplome de los salarios y una errada política industrial y agrícola que favorece más un mercado externo que uno interno. Todo esto agrava a aún más un desequilibrio territorial, en el cual solo sobresalen las regiones que son priorizadas con ventajas competitivas (vinculadas, sobre todo, al mercado externo ilas más prósperas!) y otras regiones con círculos viciosos endémicos que no son alentados por las políticas públicas, pues no se consideran con muchas más desventajas que ventajas.

Es evidente que el estancamiento de la economía mexicana tiende a hacer perdurar las desigualdades regionales. En los últimos años, no ha existido región pobre de México que haya conseguido aumentar sus ingresos para acercarse a la media, incluso las regiones de ingreso medio cuyo bienestar - medido en términos del PIB per cápita - han disminuido su participación de manera notable; se puede hablar también de un comportamiento procíclico de la dispersión de bienestar, es decir, que el auge de la economía hace más desigual al territorio nacional.

Incluso el propio FMI señala que la desigualdad de ingreso en los países pertenecientes a la Organización para la Cooperación y el Desarrollo Económico, entre los que se encuentra México, se incrementó más entre el 2010 y el 2012 que en los doce años precedentes, advirtió el FMI. La desigualdad en el ingreso llegó a un nivel históricamente elevado, atribuyéndose dicho crecimiento a la brecha de la liberalización de los flujos de capital - una de las políticas que marcaron el reciente proceso de mundialización de la economía-y a las medidas de reducción del déficit fiscal adoptadas por algunos Gobiernos (González, 2013).

El artículo elaborado por Laurece Ball, Davide Furceri y Prakash Loungani (2013), economistas y consejeros del Departamento de Investigación Económica del FMI, señala dos factores fundamentales que han contribuido a la desigualdad del ingreso. El primero es la apertura de los mercados de capitales a recursos del exterior, conocida como la liberalización de la cuenta de capital, que hace posible el flujo de recursos de un país a otro, prácticamente sin restricciones. La cuenta de capital incluye la inversión como acciones y bonos, así como préstamos bancarios. El segundo factor que genera desigualdad en el ingreso son las políticas aplicadas por los Gobiernos para reducir sus déficits presupuestales, conocidas como "consolidación fiscal".

La evidencia encontrada por los burócratas del FMI, después de analizar 58 casos de reformas de este tipo en 17 economías avanzadas, es que la liberalización de la cuenta de capital es seguida por un significativo y persistente incremento en la desigualdad. Mientras tanto, la consolidación fiscal (combinación de recorte de gastos y aumento de impuestos para reducir el déficit fiscal) ofrece resultados parecidos.

En otras palabras, como lo sostiene Robert Hunter Wade (2001), la concentración del ingreso mundial en el "quintil" más rico de la población resulta chocante, la distribución mundial del ingreso por quintiles de población; es irónico que se asemeje a una copa de champaña, con una parte superior ancha y poco profunda y un pie delgadísimo. También se ilustra con lo que nos explica Stiglitz (2012), respecto a cómo los mercados por sí solos no son eficientes ni estables y tienden a acumular la riqueza en manos de unos pocos más que a promover la competencia. Revela además cómo las políticas de Gobiernos e instituciones son propensas a acentuar esta tendencia concentradora.

El mismo Paul Krugman (2013) en un artículo publicado por el New York Times (2013) señala que se equivocan los que dicen que el mejor argumento para poner la desigualdad en un segundo plano es el estado depresivo de la economía. ¿No es más importante para restablecer el crecimiento económico que preocuparse por cómo se distribuyen los beneficios del crecimiento?

Krugman explica que esta idea no es tan acertada pues, en primer lugar si nos fijamos solo en el impacto directo del aumento de la desigualdad en estadounidenses de clase media, este es un negocio muy grande. Más allá de eso, la desigualdad probablemente jugó un papel importante en 
la creación de nuestro desastre económico, y ha jugado un papel crucial en nuestra incapacidad para limpiarlo.

Si comenzamos con los números, en promedio los estadounidenses siguen siendo mucho más pobres de lo que eran antes de la crisis económica. Por la parte inferior del $90 \%$ de las familias, este empobrecimiento refleja una tarta económica en contracción y una participación cada vez menor de ese pastel. ¿Qué era más importante? La respuesta, sorprendentemente, es que son más o menos comparables, es decir, la desigualdad está creciendo tan rápido que en los últimos seis años ha sido tan grande en un lastre para los ingresos estadounidenses comunes como los malos resultados económicos.

El Foro Económico Mundial en noviembre de 2013 lanzó su informe "Perspectivas de la Agenda Mundial 2014", que situaba el aumento de la desigualdad en los ingresos como la segunda mayor amenaza mundial de los próximos 12 a 18 meses. La desigualdad económica es perjudicial y preocupante por varias razones: además de ser moralmente cuestionable, puede repercutir negativamente en el crecimiento económico y la reducción de la pobreza, así como multiplicar los problemas sociales. ${ }^{21}$

Oxfam teme que si la desigualdad económica extrema no se controla, sus consecuencias podrían ser irreversibles, lo que daría lugar a un monopolio de oportunidades por parte de los más ricos, cuyos hijos reclamarían las tasas impositivas más bajas, la mejor educación y la mejor atención sanitaria. El resultado sería la creación de una dinámica y un círculo vicioso de privilegios que pasarían de generación en generación. La magnitud del incremento de la concentración de la riqueza, la monopolización de oportunidades y la inequidad en la

21 A lo largo del siglo XX, hay una estadística predecible que divide a la sociedad mexicana en dos partes siempre desiguales: 20 por ciento de la población concentra 65 por ciento de la riqueza y el 80 por ciento restante sobrevive con 35 por ciento de lo que queda de esa riqueza. Sin embargo, un reporte elaborado recientemente por McKinsey\&Company ( $A$ tale of Two Mexicos) muestra que esta geografía es más compleja, severa y grave de lo que se puede imaginar. representación política perfilan ya una tendencia grave y preocupante. Por ejemplo:

Así la mitad de la riqueza mundial está en manos de solo el $1 \%$ de la población; la riqueza del $1 \%$ de la población más rica del mundo asciende a 110 billones de dólares, una cifra 65 veces mayor que el total de la riqueza que posee la mitad más pobre de la población mundial; la mitad más pobre de la población mundial posee la misma riqueza que las 85 personas más ricas del mundo; siete de cada diez personas viven en países donde la desigualdad económica ha aumentado en los últimos 30 años; el $1 \%$ más rico de la población ha visto cómo se incrementaba su participación en la renta entre 1980 y 2012 en 24 de los 26 países de los que tenemos datos y en Estados Unidos, el $1 \%$ más rico ha acumulado el $95 \%$ del crecimiento total posterior a la crisis desde 2009, mientras que el $90 \%$ más pobre de la población se ha empobrecido aún más (Oxfam, 2014, p. 2).

Los sondeos de Oxfam en todo el mundo reflejan que la mayoría de la población cree que las leyes y normativas actuales están concebidas para beneficiar a los ricos. Otra reciente investigación de Oxfam respecto a trabajadores con salarios bajos en Estados Unidos revela que el $65 \%$ considera que el Congreso aprueba leyes que benefician a los ricos.

En el caso de México, la Comisión Económica para América Latina y el Caribe (Cepal) (2013) dice que el incremento de la pobreza ${ }^{22}$ en México ocurrió al tiempo que el país muestra una desigualdad en la distribución del ingreso histórica; la población que está en la punta de la pirámide tiene un ingreso 14 veces superior al del estrato más pobre. Esto quiere decir que en el 2012 la quinta parte (20\%)

22 1) La pobreza en América Latina es resultado de la desigual concentración del ingreso antes que del bajo producto o la escasez de recursos; 2) la pobreza es poco sensible al crecimiento del producto en período de alto crecimiento, pero aumenta significativamente en los periodos de crisis. 
de los hogares de mayor riqueza concentraron el $46,2 \%$ del ingreso nacional, mientras el $20 \%$ de menores percepciones apenas captaron $6,6 \%$ del ingreso total. En México, 37 de cada 100 personas viven en pobreza; otras 14 de cada 100 sobreviven en situación, según la Cepal, de indigencia. En suma, uno de cada dos mexicanos, o 51 de cada 100 , se encuentra en una condición en la que no tiene acceso a las satisfacciones esenciales que garanticen el nivel mínimo de bienestar. Entre el 2010 y el 2012 la población que estaba por debajo de la línea de bienestar en México pasó de 59,6 a 60,6 millones de personas.

Aquí hay que destacar lo que explica Boltvinik (2013) sobre los temas de desigualdad y pobreza en los que predomina la visión de que si bien ambos conceptos (y los fenómenos sociales que denotan) están estrechamente relacionados, son independientes. La pobreza no se puede reducir a la desigualdad. Puede haber comunidades con baja desigualdad y mucha pobreza, y sociedades muy desiguales con poca pobreza. Para Boltvinik, tanto desigualdad como pobreza son dos de los repugnantes rostros del sistema capitalista. Esta visión está adaptada en el hecho de que Marx puso mucho más énfasis en la explotación que en la pobreza y la desigualdad es mucho más la expresión de la explotación que la pobreza. En sociedades como la mexicana, la causa fundamental de la pobreza es la desigualdad. En la gráfica 3, se muestran las desigualdades entre tamaños de localidades donde se suman y combinan con desigualdades entre el sur y el norte del país, entre zonas indígenas y no indígenas, para producir estratificaciones sociales muy desiguales por entidad federativa que se ordenan en la gráfica de la más alta incidencia porcentual de la indigencia (Chiapas) a la más baja (Baja California Sur).

Existe un monumental contraste, sobre todo, entre Chiapas, Oaxaca, Guerrero y Puebla que tienen más de la mitad de la población (más del $70 \%$ en Chiapas) viviendo en situación de indigencia, hasta el DF, Nuevo León y las dos "Bajas", donde solo entre el $12,5 \%$ y el $15,5 \%$ viven en esa condición. Mientras en Chiapas, Oaxaca y Guerrero más del $90 \%$ de la población vive en pobreza, el dato en las cuatro entidades mejor situadas es menor a las dos terceras partes. Dato también muy contrastante es la suma de indigencia y pobreza intensa en estas últimas entidades, que es menor que la población no pobre y que la ubicada en pobreza moderada. En las tres entidades más pobres, la suma de indigencia y pobreza extrema

Gráfica 3.

Estratificación por entidad federativa

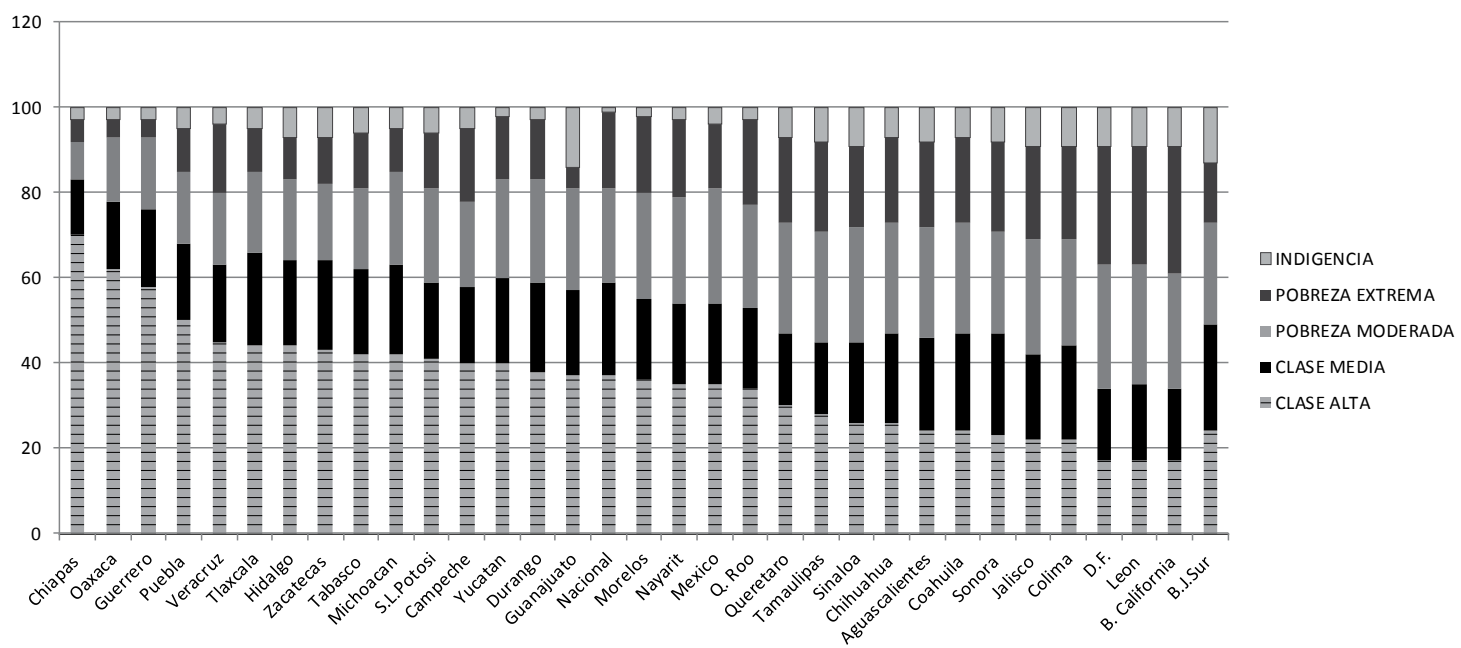

Fuente: Boltvinik (2013). 
representa tres (o más) de cada cuatro personas. En las 13 entidades mejor situadas (desde Q. Roo en adelante) el estrato más numeroso es el de pobreza moderada (que en todas ellas representa alrededor de la tercera parte de la población). En las demás entidades federativas ocupan este lugar los indigentes.

En México y otros países la cuestión cobra signos alarmantes, pues la pobreza tiene potencial para limitar el crecimiento económico al restringir el tamaño de los mercados, la pobreza da lugar a bajo crecimiento, que a su vez genera más pobreza, creando círculos viciosos (Myrdal, 1957). Incluso el BM (2005) reconoce que la desigualdad puede ser un obstáculo para el crecimiento y reducción de la pobreza. La expectativa de disminuir la pobreza se agota, ya que México ha registrado un nulo o muy bajo crecimiento junto a una distribución regresiva del ingreso. ${ }^{23}$

El drama se expande y cobra ya no solo visos monocausales, sino multifactoriales regionales que son muy difíciles de destrabar, pues se suma una caída vertiginosa en el PIB industrial y agrícola nacional, regional y local, socavado por un debilitamiento del "Estado Fallido"24 que pierde el control o la maniobra de su gobernabilidad institucional; todo esto contrarrestado por el poder de redes o grupos de narcotraficantes que se apropian del espacio (se cobra derecho de piso) a través de disputas territoriales para salvaguardar sus negocios

23 A lo largo del siglo XX, hay una estadística predecible que divide a la sociedad mexicana en dos partes siempre desiguales: $20 \%$ de la población concentra $65 \%$ de la riqueza y el $80 \%$ restante sobrevive con $35 \%$ de lo que queda de esa riqueza. Sin embargo, un reporte elaborado recientemente por McKinsey y Company (A tale of Two Mexicos) muestra que esta geografía es más compleja, severa y grave de lo que se puede imaginar.

24 "El fracaso del estado se ha definido como su incapacidad para proveer los bienes políticos fundamentales asociados con la estatalidad: seguridad física, instituciones políticas legítimas, administración de la economía y bienestar social. La mayoría de las definiciones hacen referencia al funcionamiento del estado e intentan medir su capacidad (performance). Así se entiende que un estado fracasa si es deficiente en áreas como seguridad, el sistema político, el estado de derecho, la administración y el bienestar social. Esta deficiencia hace que el estado sea incapaz de 'establecer un monopolio legítimo del uso de la fuerza física y de proteger a sus ciudadanos de la violencia" (Tedesco, 2007). ilícitos (siembra de estupefacientes o distribución por cuotas de mercado de sus productos). Esto ocasiona daños irreversibles al tejido productivo asentado en una determinada región y se expresa en su aniquilamiento y deterioro exponencial; otros llaman a esta pérdida absoluta de la integridad del patrimonio productivo "vaciamiento productivo", 25 que no es más que el quebranto de la dinámica de valorización de capital que, lejos de recrearse, se descompone por lo que estamos en presencia de un capitalismo degenerativo. ${ }^{26}$

Cabe destacar las estimaciones econométricas que realizan Asuad et al. (2007) para el 2012 y el 2020 sobre desigualdades regionales. Los autores mencionan que de continuar el actual modelo neoliberal las desigualdades regionales tenderán a ampliarse hacia 2020, dado que prácticamente no cambiaría la situación en términos de la desigualdad del ingreso per cápita entre entidades federativas, como se muestra en las tablas 4 y 5 .

En estas, se valora que las entidades federativas dominantes para el 2012 y el 2020 serán las de siempre: Distrito Federal, Estado de México, Nuevo León, Jalisco y Coahuila. Las desigualdades regionales tienden a ampliarse y prácticamente no cambian en términos de desigualdad del ingreso per cápita entre entidades federativas. Por otro lado, los Estados con menor crecimiento per cápita para los mismos años serán Zacatecas, Baja California Sur, Tlaxcala, Colima y Nayarit.

Recapitulando, el desarrollo de cada Estado - localidad depende fundamentalmente de las tendencias de crecimiento y desarrollo que se den en los otros Estados o localidades, ya que como subsistemas abiertos deben analizarse teniendo en cuenta tanto el sistema en su totalidad, como las partes que lo componen; esto debido a que los Estados forman parte de un desarrollo regional

\footnotetext{
25 Una discusión más amplia de la idea del vaciamiento productivo de México se presenta en Isaac y Quintana (2012).

26 Un capitalismo degenerativo que se expresa en poblaciones desplazadas (abandonan sus lugares de origen) por carteles de la droga que destruyen no solo el tejido productivo, sino también social o la conformación de grupos de autodefensa que se integran por la incapacidad del Estado de ofrecer seguridad social y jurídica a sus pobladores.
} 
Tabla 4.

Estimaciones del comportamiento del ingreso per cápita para 2020. Tendencias de mediano y largo plazo del PIB per cápita por entidad federativa

\begin{tabular}{|c|c|c|}
\hline Entidad federativa & 2012 & Participación relativa \\
\hline Distrito Federal & 359955 & 0,209 \\
\hline Estado de México & 177037,9 & 0,1028 \\
\hline Nuevo León & 118394,2 & 0,0687 \\
\hline Jalisco & 109871,4 & 0,0638 \\
\hline Chihuahua & 85742,2 & 0,0498 \\
\hline Veracruz & 71747,2 & 0,0417 \\
\hline Tamaulipas & 63307,5 & 0,0368 \\
\hline Baja California & 62432,6 & 0,0362 \\
\hline Guanajuato & 61244,9 & 0,0356 \\
\hline Puebla & 56818,3 & 0,033 \\
\hline Coahuila & 56429,9 & 0,328 \\
\hline Promedio nacional & 53825,4 & \\
\hline Sonora & 45915,3 & 0,0267 \\
\hline Michoacán & 41134,6 & 0,0239 \\
\hline Sinaloa & 36066,5 & 0,0209 \\
\hline San Luis Potosi & 31913,3 & 0,0185 \\
\hline Chiapas & 28808,2 & 0,0167 \\
\hline Querétaro & 27379,6 & 0,0159 \\
\hline Aguascalientes & 26490,6 & 0,0154 \\
\hline Guerrero & 26432,4 & 0,0153 \\
\hline Quintana Roo & 26232,2 & 0,0152 \\
\hline Morelos & 26218,9 & 0,0152 \\
\hline Oaxaca & 25425,4 & 0,0148 \\
\hline Yucatán & 24811,3 & 0,0144 \\
\hline Hidalgo & 23510,4 & 0,0136 \\
\hline Durango & 22206,9 & 0,0129 \\
\hline Campeche & 18902,8 & 0,011 \\
\hline Tabasco & 17553 & 0,0102 \\
\hline Zacatecas & 13714,9 & 0,008 \\
\hline Colima & 9638,4 & 0,0056 \\
\hline Nayarit & 9226,2 & 0,0054 \\
\hline Baja California Sur & 8997 & 0,0052 \\
\hline Tlaxcala & 8790,4 & 0,0051 \\
\hline
\end{tabular}

Fuente: elaboración del autor a partir de datos de Asuad et al. (2007). 
Tabla 5.

Estimaciones del comportamiento del ingreso per cápita para 2020. Tendencias de mediano y largo plazo del PIB per cápita por entidad federativa

\begin{tabular}{|c|c|c|}
\hline Entidad federativa & 2020 & Participación relativa \\
\hline Distrito Federal & 404841,4 & 0,2096 \\
\hline Estado de México & 208221,5 & 1078 \\
\hline Nuevo León & 129550,1 & 0,0671 \\
\hline Jalisco & 125318,1 & 0,0649 \\
\hline Chihuahua & 99667,8 & 0,0516 \\
\hline Veracruz & 79579,3 & 0,0412 \\
\hline Tamaulipas & 69270,1 & 0,0359 \\
\hline Guanajuato & 67052,1 & 0,0347 \\
\hline Baja California & 66005,4 & 0,0342 \\
\hline Puebla & 65081,4 & 0,0337 \\
\hline Coahuila & 63278 & 0,0328 \\
\hline Promedio nacional & 60371,6 & \\
\hline Sonora & 51471,2 & 0,0266 \\
\hline Michoacán & 46597,8 & 0,0241 \\
\hline Sinaloa & 40512 & 0,021 \\
\hline San Luis Potosí & 38211,2 & 0,0198 \\
\hline Aguascalientes & 33341,1 & 0,0173 \\
\hline Oaxaca & 30448 & 0,0158 \\
\hline Morelos & 29698,2 & 0,0154 \\
\hline Guerrero & 29271,3 & 0,0152 \\
\hline Chiapas & 29032,6 & 0,015 \\
\hline Yucatán & 28526,5 & 0,0148 \\
\hline Hidalgo & 28253,6 & 0,0146 \\
\hline Querétaro & 27359,8 & 0,0142 \\
\hline Quintana Roo & 25425,9 & 0,0132 \\
\hline Durango & 24455,6 & 0,0127 \\
\hline Campeche & 18902,9 & 0,0098 \\
\hline Tabasco & 17752 & 0,0092 \\
\hline Zacatecas & 15247,5 & 0,0079 \\
\hline Colima & 10810,7 & 0,0056 \\
\hline Tlaxcala & 10139,4 & 0,0052 \\
\hline Nayarit & 9642,9 & 0,005 \\
\hline Baja California Sur & 8926,2 & 0,0046 \\
\hline
\end{tabular}

Fuente: elaboración del autor a partir de datos de Asuad et al. (2007). 
nacional. Así, los Estados y localidades se pueden caracterizar con referencia a sí mismos, a otras unidades del mismo conjunto, a la estructura del conjunto, a las subunidades y a las súperunidades.

La caracterización económica sobre la que un Estado contribuye poco o mucho al PIB per cápita nacional dependerá de sus condiciones económicas internas, pero también de su entorno nacional. Estos factores espaciales (nacionales y regionales) propician desequilibrios económicos inter e intra, en los órdenes local, regional y nacional.

La política neoliberal de México en vez de reducir las desigualdades regionales ha tendido más bien a ahondarlas. Una de las razones que ha ayudado a reproducir dichas desigualdades inter intra, es aplicar políticas discriminatorias a favor del impulso de áreas con ventajas competitivas, dejando de lado las que no cuentan con dichas ventajas. Este escenario de regiones marginales (no competitivas) y "prósperas" (competitivas) agrava más la problemática territorial, pues se expresa en una raquítica generación de empleos, en un desplome de salarios y en un incremento dramático en la espiral de la pobreza.

\section{CONCLUSIONES}

Se ha analizado cómo el Estado no cumple con sus compromisos de salvaguardar o generar condiciones para que se reviertan o se contrapesen las desigualdades regionales; al contrario, tenemos un Estado que genera más problemas donde debería haber soluciones y donde se trate de aminorar o contrarrestar sinergias negativas en favor de espacios o regiones que muestran signos inequívocos de estancamiento. También hay que mencionar que el Estado, en ciertas localidades del territorio nacional, ha perdido capacidad de acción o maniobra que garantice estabilidad social y económica a los ciudadanos que habitan en entidades secuestradas por grupos delictivos. La agenda del Estado mexicano tiene pendiente ofrecer seguridad a las poblaciones que están inertes y desamparadas, ante los actos de despojo que aplican los grupos delincuenciales en sus distintas variantes.

En síntesis, ¿qué es lo que particulariza el desarrollo intrarregional divergente en México? La respuesta sin lugar a dudas es que la dinámica económica de México se puede caracterizar como la acentuación o agudización del desequilibrio nacional, regional y local entre sus regiones e incluso es un proceso circular que aleja constantemente a las regiones que la integran en el tiempo. Es claro que se producirán efectos que retroalimentan el proceso de concentración espacial debido a que las inversiones y las decisiones sobre la utilización del excedente económico se irán a todos los puntos que cuenta con las características y condiciones más favorables para una producción rentable y competitiva. Así, se fomenta un crecimiento desigual con disparidades regionales cada vez más acentuadas.

Como se ha explicado, el patrón de desarrollo regional en México se caracteriza por una elevada concentración económica y poblacional en unas cuantas regiones y localidades urbanas, producto de las diferencias en la formación de áreas de mercado, la aglomeración del capital fijo y en las productividades globales y sectoriales de sus economías. Los problemas estructurales del desarrollo económico y social se expresan "espacialmente", dando lugar a las desigualdades económicas y sociales entre regiones, las cuales se manifiestan mediante la concentración y dispersión de la actividad económica; la transición demográfica en las distintas regiones y la concentración y dispersión de la población en el territorio nacional. 


\section{REFERENCIAS}

1. Ayala, D. (2007b, 29 de octubre). La pobreza desde distintas ópticas. Reporte Económico de la Jornada. Recuperado de http://www.jornada.unam.mx/2007/10/29/index

2. Ayala, D. (2014). Oxfam. Desigualdad económica y secuestro democrático Recuperado de http://www.jornada. unam.mx/2014/02/10/opinion/030o1eco

3. Asuad, N., Quintana, L. \& Ramírez, R. (2007). Desarrollo y políticas en México: retos y perspectivas 2006-2020. Agenda para el desarrollo, 13, 231-247.

4. Ball, L., Furceri, D., Leigh, D. \& Loungani, P. (2013). The Distributional Effects of Fiscal Consolidation. IMF Working Paper. Recuperado de http://www.imf.org/external/pubs/ft/wp/2013/wp13151.pdf

5. Banco Mundial. (1992). Governance and Development. Washington, D. C.: The World Bank. Recuperado de http://documents.worldbank.org/curated/en/1992/04/440582/governance-development

6. Banco Mundial. (2005). Informe sobre el desarrollo mundial 2006. Equidad y desarrollo. Washington, D. C.: Banco Mundial.

7. Barkin, D. \& Timothy, K. (1970). Desarrollo económico regional. Enfoque por cuencas hidrológicas en México. México: Siglo XXI.

8. Boltvinik, J. (2001). Planes, desigualdad y pobreza. La Jornada. Recuperado de Recuperado de http://www. jornada.unam.mx/2001/06/22/022a1eco.html

9. Boltvinik, J. (2013). Economía Moral. Recuperado de http://www.jornada.unam.mx/2013/09/20/ opinion/034oleco

10. Brenner, N. y Theodore, N. (2002). Cities and the geographies of "actually existing neoliberalism". Antipode, 34(3). Recuperado de https://dx.doi.org/10.1111/1467-8330.00246

11. Calva, J. (2005). México: la estrategia macroeconómica 2002-2006. Promesas, resultados y perspectivas. Problemas de desarrollo, 36(143), 59-87.

12. Calva, J. (2007). Prólogo de la macroeconomía del crecimiento sostenido (vol. 4). Ciudad de México: UNAM, Porrúa.

13. Chavéz, M. (2001). Reflexiones en torno al tema "Globalización con desarrollo: es posible formular un modelo sustitutivo de la sustitución de importaciones y del Consenso Washington”. El Colegio de México. Recuperado de http://www.colmex.mx/informacion_academica/centros/cee/procientec/index.htm

14. Chavéz, M. (2007). De la macroeconomía de la inestabilidad y el estancamiento hacia la recuperación del desarrollo. En J. Calva (coord.), De la Macroeconomía del crecimiento sostenido (vol. 4). México D. F.: UNAM, Porrúa.

15. Comisión Económica para América Latina y el Caribe (Cepal). (1996). Quince años de desempeño económico. América Latina y el Caribe, 1980-1995 (n. $\left.{ }^{\circ} 43\right)$. Santiago de Chile: ONU.

16. Comisión Económica para América Latina y el Caribe (Cepal). (2006). Hacia el objetivo del milenio de reducir la pobreza en América Latina y el Caribe. Santiago de Chile: Cepal.

17. Comisión Económica para América Latina y el Caribe (Cepal). (2006). América Latina y el Caribe: proyecciones 2006-2007. Centro de Proyecciones Económicas. División de Estadística y Proyecciones Económicas. Santiago de Chile: Cepal. 
18. Comisión Económica para América Latina y el Caribe (Cepal). (2006). Panorama social en América Latina. Santiago de Chile: Cepal.

19. Comisión Económica para América Latina y el Caribe (Cepal). (2013). Panorama social de América Latina. Santiago de Chile: Cepal.

20. Cornia, G. (1987). Adjustment with a human fase. Oxford: Oxford University Press.

21. Encuesta Nacional de Ocupación y Empleo [ENOE]. (2010). México D. F.: ENOE.

22. Fondo Monetario Internacional (FMI). (2007). Perspectivas de la economía mundial. Washington, D. C.: FMI.

23. Fernández, A., Parejo, J. \& Rodríguez, L. (1995). Política económica. México, D. F.: Siglo XXI.

24. Ffrech, D. (2005). Reformas para América Latina después del fundamentalismo neoliberal. Santiago de Chile: Siglo XXI, CEPAL.

25. González, R. (2014). Acaparan 206 mil inversionistas el $42 \%$ de la riqueza mexicana. Recuperado de http:// www.jornada.unam.mx/2014/02/12/economia/027n1eco

26. Guillén, H. (2005). México frente a la mundialización neoliberal. México, D. F.: Ediciones Era.

27. Guillén, A. (2007). Obstáculos macroeconómicos para la instauración de un proyecto nacional de desarrollo alternativo. En J. Calva (Coord.), De la Macroeconomía del crecimiento sostenido (vol. 4). México, D. F.: UNAM, Porrúa.

28. Huerta, A. (2004). La economía política del estancamiento. México: Editorial Planeta Mexicana.

29. Huerta, A. (2006). Alternativas de política para el crecimiento sostenido. Economía Informa, 3(7), 52-169.

30. Hunter, R. (2001). La creciente desigualdad en la distribución del ingreso. Recuperado de http://www.imf.org/ external/pubs/ft/fandd/spa/2001/12/pdf/wade.pdf

31. Ibarra, D. (2004). Los laberintos del orden internacional: la importación de reformas. Revista de Cepal, 82, 17.

32. Isaac, J. \& Quintana, L (2012). Industria y vaciamiento productivo regional en México. En J. Calva (Coord.), Desarrollo regional y urbano. Análisis estratégico para el desarrollo (vol. 13, pp. 39-64). México, D. F.: Juan Pablos.

33. Krugman, P. (2013). Why incuality matters. Recuperado de http://www.nytimes.com/2013/12/16/opinion/ krugman-why-inequality-matters.html

34. Mañan, O. (2004). La condicionalidad estructural de las IFIS y la autonomía de la política económica: critica a los argumentos de impotencia. Revista Problemas de desarrollo, 35(139), 82-102.

35. Merchand, M. (2007). Teorías y conceptos de economía regional y estudios de caso. Puerto Vallarta, Jalisco: Universidad de Guadalajara.

36. Nadal, A. (2010). Contradicciones del modelo de economía abierta. Programa sobre ciencia, tecnología y desarrollo. Documento de trabajo No.1-01. Ciudad de México: Colegio de México.

37. Ros, J. (2004). Teorías del desarrollo y la economía del crecimiento. Ciudad de México: Fondo de Cultura Económica.

38. Sapri. (2002). Las políticas de ajuste estructural en las raíces de la crisis económica y la pobreza. Red Internacional de la Sociedad Civil para la Revisión Participativa de las Políticas de Ajuste Estructural (SAPRIN). Recuperado de http://www.saprin.org/SAPRIN_Exec_Summ_Esp.pdf 
39. Secretaría del Trabajo y Previsión Social (STPS) (2013). Diario Oficial de la Federación de 2013. Ciudad de México: STPS.

40. Stiglitz, J. (2002). El malestar en la globalización. Madrid: Taurus.

41. Stiglitz, J. (2003). El rumbo de las reformas, hacia una nueva agenda para América Latina. Revista de la Cepal, 80, 56-72.

42. Stiglitz, J. (2012). El precio de la desigualdad. Madrid: Taurus.

43. Tedesco, L. (2007). El Estado en América Latina: ifallido o en proceso de formación? Madrid: Fundación Fride.

44. Tello, C. \& Ibarra, J. (2013). La revolución de los ricos. Ciudad de México: Universidad Autónoma de México.

45. United Nations Conference on Trade and Development (Unctad). (2004). Los países menos adelantados. New York: Unctad. 